\title{
Consequences of post-weaning social isolation on anxiety behavior and related neural circuits in rodents
}

\author{
Jodi L. Lukkes' ${ }^{1}$ Michael J. Watt ${ }^{2}$, Christopher A. Lowry' ${ }^{1}$ and Gina L. Forster ${ }^{2}$ * \\ Department of Integrative Physiology, University of Colorado at Boulder, Boulder, CO, USA \\ Division of Basic Biomedical Sciences and Neuroscience Group, Sanford School of Medicine, University of South Dakota, Vermillion, SD, USA
}

Edited by:

Anne Z. Murphy,

Georgia State University, USA

Reviewed by:

Frank S. Hall, National Institute on Drug

Abuse, USA

Cheryl McCormick, Brock University,

Canada

\section{*Correspondence:}

Gina L. Forster, Division of Basic

Biomedical Sciences, Sanford School

of Medicine, University of South

Dakota, 414 East Clark Street,

Vermillion, SD 57069-2390, USA.

e-mail:gforster@usd.edu
Exposure to adverse experiences in early-life is implicated in the later vulnerability to development of psychiatric disorders, including anxiety and affective disorders in humans. Adverse early-life experiences likely impart their long-term consequences on mental health by disrupting the normal development of neural systems involved in stress responses, emotional behavior and emotional states. Neural systems utilizing the neurotransmitters serotonin, dopamine and the neuropeptide corticotropin-releasing factor (CRF) are implicated in mediating emotive behaviors, and dysfunction of these neurochemical systems is associated with mood/anxiety disorders. These neural systems continue maturing until early or mid-adolescence in humans, thus alterations to their development are likely to contribute to the long-term consequences of adverse early-life experiences. A large body of literature suggests that post-weaning isolation rearing of rodents models the behavioral consequences of adverse early-life experiences in humans. Overall, the majority findings suggest that post-weaning social isolation that encompasses pre-adolescence produces long-lasting alterations to anxiety behavior, while measures of monoaminergic activity in various limbic regions during social isolation suggest alterations to dopamine and serotonin systems. The goal of this review is to evaluate and integrate findings from post-weaning social isolation studies specifically related to altered fear and anxiety behaviors and associated changes in neuroendocrine function and the activity of monoaminergic systems.

Keywords: isolation, CRF, fear, serotonin, rat, dopamine, stress, anxiety

\section{INTRODUCTION}

Clinical and preclinical data implicate adverse early-life experiences in the later development of psychiatric and substance abuse disorders (Gutman and Nemeroff, 2003; Lapiz et al., 2003; National Clearinghouse on Child Abuse and Neglect Report, 2005; Fone and Porkees, 2008). Although other covariates including genetic predisposition should be taken into account, approximately $80 \%$ of young adults who report early-life neglect or abuse are diagnosed with at least one psychiatric disorder, including anxiety disorders, affective disorders, schizoaffective disorders or behavioral disorders (Gutman and Nemeroff, 2003; Lapiz et al., 2003; McFarlane et al., 2005; National Clearinghouse on Child Abuse and Neglect Report, 2005; Espejo et al., 2007; Fone and Porkees, 2008; Heim et al., 2008). Adverse early-life events also increase the likelihood of co-morbid psychiatric and substance abuse disorders in adulthood (SchellerGilkey et al., 2003). Thus, severe or chronic adverse early-life experiences impose serious long-term costs on the individual as well as health, social, and judicial systems. It is therefore of importance to understand the effects of adverse early-life experiences on neural mechanisms underlying mood and anxiety states.

In both humans and rodents, neurotransmitter systems implicated in modulation of emotive behaviors, such as serotonin (5-hydroxytryptamine: 5-HT), dopamine (DA) and corticotropin-releasing factor (CRF), do not mature fully until early-to-late adolescence (Insel et al., 1988; Spear, 2000; Andersen, 2003; Vazquez et al., 2006). Therefore, it is possible that normal development of neurochemical systems involved in regulation of stress responses, mood and anxiety states during adulthood is susceptible to disruption by adverse experience in early-life. Moreover, clinical and preclinical studies suggest that perturbations to these neurochemical systems during early-life appear to have long-lasting consequences on emotional behavior in rodents and on mental health in humans (Gutman and Nemeroff, 2003; Lapiz et al., 2003; Nemeroff, 2004; Plotsky et al., 2005; Fone and Porkees, 2008; Heim et al., 2008). A large body of literature suggests post-weaning isolation rearing of rodents is one procedure that models some of the behavioral consequences of adverse earlylife experiences in humans. Therefore, the goal of this review is to evaluate and integrate classic and recent findings of the consequences of post-weaning social isolation on fear and anxiety-related behaviors, and potential neurobiological mechanisms underlying these changes in behavior, including alterations in neuroendocrine function and $\mathrm{CRF} /$ monoaminergic activity.

\section{POST-WEANING SOCIAL ISOLATION OF RODENTS}

Neural and behavioral development of rodents mirrors stages of human development. While the period from weaning to early adulthood is often referred to as adolescence for rodents, discrete developmental stages based on numerous neurobiological and behavioral studies can be identified (as recently reviewed by McCormick et al., 2009). For the purposes of this discussion, rat postnatal day (PD) 21 (earliest day of weaning) to PD28 
corresponds to pre-adolescence, $\mathrm{PD} 28$ to $\mathrm{PD} 34$ corresponds to early adolescence, PD34 to PD46 corresponds to mid-adolescence, PD46 to PD56 corresponds to late adolescence, and PD56 can be considered early adulthood (Spear, 2000; Andersen, 2003; Laviola et al., 2003). Studies of post-weaning social isolation in rodents have manipulated rearing conditions during different periods of this developmental window. A large number of studies employ chronic ( $>1$ week continuous) post-weaning social isolation, also termed isolation rearing, as a rodent model of adverse early-life experience or social deprivation (as already discussed by Hall, 1998; Gutman and Nemeroff, 2003; Lapiz et al., 2003; Fone and Porkees, 2008), and this specific model is the focus of this review. The vast majority of long-term post-weaning isolation studies utilize male rats, and the findings reviewed below and in Tables 1 and 2 are derived from males unless otherwise specified.

Post-weaning social isolation involves rearing rats in isolation from the day of weaning, (which is imposed by the experimenter and can range from PD21 to PD28 across studies) until the day of testing typically in late-adolescence or adulthood. Isolation-reared rats are housed within the same holding room as group-reared control rats, with the latter typically housed in groups of three to five rats per cage. Thus, socially isolated rats are completely deprived of social contact but still have access to olfactory, auditory and visual cues from other rats within the holding room (Lapiz et al., 2003; Fone and Porkees, 2008). Environmental enrichment reverses some of the effects of post-weaning social isolation (Hellemans et al., 2004; Hoffmann et al., 2009), suggesting that enrichment should not be used for standard isolation procedures. Interestingly, the strain of rat used may also alter the outcome of post-weaning social isolation. For instance, hyper-locomotion in a novel openfield is commonly observed following social isolation of male Lister Hooded rats, but this finding is not consistently replicated with male Sprague-Dawley rats (Leng et al., 2004; Weiss et al., 2004; Lukkes et al., 2009a,c).

In the vast majority of post-weaning social isolation studies, rats remain in isolation for 4-6 weeks or more (as reviewed by Lapiz et al., 2003; Fone and Porkees, 2008) and are then tested while still in isolation-housed conditions. Thus, rats are tested in a current state of social deprivation in addition to being reared in isolation during post-weaning development (Potegal and Einon, 1989; Hall, 1998). Unless otherwise specified, the studies discussed in subsequent sections involve the testing of male isolation-reared rats in a current state of social deprivation. To assess the effects of post-weaning social isolation in the absence of current social deprivation, models of post-weaning social isolation have been developed where male rats were isolated from weaning (PD21-22) to mid-adolescence (PD35 or 42) and then re-housed in groups until testing in later adolescence or early adulthood (e.g. Potegal and Einon, 1989; van den Berg et al., 1999; Lukkes et al., 2009a-c). This approach has been very valuable in determining the long-term effects of isolation rearing on later behavioral and neural measures. However, further considerations need to be made to specify the effects of post-weaning social isolation. For example, comparing the effects of short-term ( $<1$ week) social isolation immediately prior to testing vs. chronic post-weaning isolation may allow the contributions of social deprivation to the effects of chronic post-weaning isolation to be further elucidated. Furthermore, a comparison of the effects of isolation-rearing from post-weaning to adulthood with the effects of adult isolation of an equivalent length of time will serve to determine whether pre-adult isolation represents the critical period for this procedure (e.g. Einon and Morgan, 1977). While these critical comparisons have been made across studies (e.g. Hall, 1998), this field will be significantly advanced by the inclusion of these controls within the same study.

Literature reviewed in subsequent sections suggests that social isolation from weaning to early adulthood represents an experience that can substantially alter the expression of emotive behaviors. The behavioral consequences of post-weaning social isolation, particularly on expression of social behaviors during later adolescence and adulthood, have been attributed to post-weaning deprivation of play behavior (e.g. Potegal and Einon, 1989; van den Berg et al., 1999, and as reviewed by Hall, 1998). In support of this, Einon and colleagues (Einon et al., 1978, 1981; Potegal and Einon, 1989) demonstrated that male rats isolated from PD20 or 25 to PD45 or 50 were protected from the long-term consequences of social isolation on later behaviors (such as heightened aggression or hyper-activity in a novel environments) if rats were allowed daily bouts of play with a conspecific. In species that normally do not show significant play behavior as juveniles and adolescents, these behavioral consequences of post-weaning social isolation are not long-lasting, and their emergence in the short-term is not alleviated by daily play bouts (Einon et al., 1981). Overall, play deprivation during the post-weaning developmental period for rats may underlie alterations to later social behaviors or hyper-activity in novel environments, but a similar relationship for anxiety-like and fear behaviors needs clarification.

\section{EFFECTS OF POST-WEANING SOCIAL ISOLATION ON ANXIETY AND FEAR BEHAVIOR ANXIETY}

Post-weaning social isolation is often but not always associated with increased anxiety-like behavior (as reviewed by Hall, 1998; Fone and Porkees, 2008). However, whether altered anxiety states associated with post-weaning social isolation are a long-term consequence of social isolation during a critical window of development or simply an effect of current state of social deprivation needs to be considered. For example, Einon and Morgan (1977) demonstrated that female and male rats reared in isolation from pre- to midadolescence (PD25 to PD45) exhibited increased latency to emerge into an unfamiliar open-field when tested at PD45. However, this effect appears to be a function of social deprivation at the time of testing, given that different age ranges of isolation produced similar effects but only if the rats were living in isolation at the time of testing (Einon and Morgan, 1977). Furthermore, the effects of isolation on open-field emergence of male rats in particular, were reversed by re-socialization prior to testing (Einon and Morgan, 1977). Similarly, male and female rats isolated from pre- to mid-adolescence (PD26 to PD40) showed increased latency to emerge into an unfamiliar open-field, decreased center entries and decreased defensive burying (indicative of reduced proactive coping) when tested at PD40 in a state of social deprivation (Arakawa, 2005, 2007). The effects of isolation-rearing initiated at PD26 did not appear to be due to current state of social deprivation, since the majority of anxiety-like behaviors exhibited by male isolation-reared rats 
were not reversed by 25, 40 or 90 days of re-socialization (Arakawa, 2005,2007 ). There was no effect of the same length (15 days) of isolation-rearing on male behavior if isolation was initiated in late adolescence (PD51; Arakawa, 2005), suggesting an earlier critical window for the effects of social isolation on anxiety-like behaviors. Furthermore, initiating isolation-housing in adulthood (PD66 or PD116) actually increased both open-field center entries and defensive burying (Arakawa, 2005, 2007), suggesting that adult social isolation may result in decreased anxiety-like behaviors. In contrast, social isolation of female rats at both earlier (pre- to midadolescence) and later times (adulthood, e.g. P66 to P80) reduced defensive burying (Arakawa, 2007). Overall, these latter studies suggest social isolation rearing of male rats must occur during a critical window (pre- to mid-adolescence) to result in long-lasting increases in anxiety-like behaviors that are not reversed by resocialization. In contrast, a critical period may not apply for female rats. Instead, social isolation at any age may enhance anxiety states in female rats, which requires further testing.

Further support for pre-adolescence as an important period for post-weaning social isolation of male rats has been suggested by studies assessing the long-term impact of post-weaning social isolation on later social interaction. Similar to Arakawa's findings, male rats isolated from pre- to mid-adolescence (PD21 to PD42) and re-socialized until testing in early adulthood (PD59) exhibited increased latency to enter the center of a familiar but brightlylit open-field when compared to group-reared rats (Lukkes et al., 2009a). These rats also exhibit decreased social interaction and increased freezing behavior during a social interaction test with an unfamiliar conspecific (Lukkes et al., 2009a,c), indicative of higher anxiety-like behavior (Lowry et al., 2005). Likewise, van den Berg et al. (1999) found that male rats reared in isolation from preadolescence to the onset of mid-adolescence (PD22 to PD35) and then re-socialized until testing in mid-adolescence (PD42) exhibited decreased social approach, although it should be noted that these rats did not show altered anxiety-like behavior in the elevated plus-maze (EPM). Like Arakawa (2005), the findings of greater anxiety states in social and sometimes non-social environments (van den Berg et al., 1999; Lukkes et al., 2009a,c) could not be attributed to current state of social deprivation given that rats were socially housed for 1 or 2 weeks prior to testing. Therefore, there is evidence that post-weaning social isolation has long-term effects on anxiety-like behaviors. However, the caveat should be made that re-socialization in the studies described above has involved isolates re-socialized with other isolates, which may result in quite different social group dynamics as compared to re-socialized group-reared rats. Thus, the effects of social isolation and then re-socialization with group-reared rats on anxiety-like behaviors needs to be determined to fully clarify the impact of isolation-rearing on later social behavior and related anxiety states.

As previously mentioned, not all studies show that post-weaning social isolation alters anxiety-like behaviors, and there have been reports of re-socialization reversing heightened anxiety states following social isolation (e.g. Einon and Morgan, 1977; Hall, 1998; Fone and Porkees, 2008). The differing findings in relation to the expression of heightened anxiety states may be a result of varying adversities inherent in the different test paradigms (Hall, 1998; Hall et al., 2000), differing isolation onset and duration, or may represent strain differences between Lister Hooded rats (Einon and Morgan, 1977) vs. Sprague-Dawley and Wistar rats (van den Berg et al., 1999; Arakawa, 2005, 2007; Lukkes et al., 2009a,c). By comparing across studies that have used the same behavioral end-measure, such as the EPM, the effects of isolation onset and duration on later anxiety measures can be better evaluated. Overall, regardless of rat strain and isolation duration, isolation-rearing initiated during pre-adolescence (PD21-PD28) appears to decrease time and entries into open arms of the EPM for male rats, indicative of increased anxiety-like behaviors. For example, Weiss et al. (2004) isolated rats from PD21 until day of EPM testing in adulthood (PD91), and found the male but not female rats exhibited increased anxiety-like behaviors. Wright et al. (1991) similarly showed that social isolation from pre- to late adolescence (PD21-PD51) resulted in increased anxiety-like behaviors in the EPM, which was not alleviated by resocialization for 30 days. Shorter periods of isolation also appear to increase anxiety states if initiated in pre-adolescence, with male rats exposed to 3 weeks of isolation from PD22 to PD43 showing decreased exploration in the EPM, albeit tested while in social isolation (Parker and Morinan, 1986). In contrast, Brenes et al. (2009) initiated isolation at a later age and isolated male rats from early adolescence to early adulthood (PD28 to PD60). These investigators found no effect of isolation-rearing on anxiety-like behavior in the EPM when tested on PD62 (Brenes et al., 2009). Similarly, a shorter isolation period that only encompassed early to mid-adolescence (PD30-35) did not affect male rat anxiety behavior when tested on the EPM at PD36, but did reduce time spent in open arms for female rats (Leussis and Andersen, 2008). Like Arakawa (2005, 2007), Thorsell et al. (2006) highlight an apparent anxiolytic effect of social isolation-rearing for male rats in the EPM and open-field when social isolation is initiated in later adolescence (PD45, midadolescence). Combined, it appears that a common factor shared by studies where isolation rearing of male rats is associated with increased anxiety-states, which are not reversed by re-socialization, is the earlier initiation of isolation (typically PD21-PD26, pre-adolescence). In contrast, studies that initiate isolation-rearing later (in most cases PD28 - early adolescence, or later) show no alterations or decreased anxiety-related behavior. Thus, the initiation of social isolation in pre-adolescence could be important for later emergence of long-term anxiety-like states for male rats. Interestingly, play behavior of rats is initiated at this pre-adolescence stage (PD18-28) and peaks at PD32-40 (Panksepp, 1981). This suggests that the deprivation of play behavior at the time this behavior normally emerges may relate to increased anxiety states in male rats, which warrants further testing. The limited number of studies that have used female rats precludes similar comparisons, but one common finding is that isolation rearing and/or social deprivation appears to increase anxiety-like behavior of female rats regardless of onset of isolation (e.g.; Arakawa, 2007; Leussis and Andersen, 2008). Therefore, whether male and female rats share a similar critical period for the impact of social isolation on anxiety-like behaviors needs further investigation.

\section{FEAR}

Fewer studies have examined the effects of post-weaning social isolation on fear-related behavior. Isolation-rearing of male SpragueDawley rats from pre- to mid-adolescence (PD21-42) followed 
by re-socialization for 2 weeks did not alter unconditioned fear behavior (freezing) in response to repeated mild foot-shock (Lukkes et al., 2009a). Longer isolation periods that were also initiated at PD21 similarly revealed no effect of social isolation on unconditioned fear behavior when male or female rats were tested in a current state of social deprivation (Fulford and Marsden, 1998a,b; Weiss et al., 2004). Therefore, social isolation that is initiated in preadolescence and encompasses early or entire adolescence appears to have little effect on unconditioned fear behavior in response to mild foot-shock.

Contrasting results have been obtained regarding the effects of social isolation on conditioned fear behaviors. Lukkes et al. (2009a) show that male Sprague-Dawley rats reared in isolation (PD21-42) and re-socialized prior to testing (PD42-56) exhibited elevated conditioned fear behavior to a tone previously paired with footshock when compared to group-reared rats. However, other studies observed no differences in fear behavior in response to a conditioned tone between isolation- and group-reared male or female Sprague-Dawley and Lister Hooded rats (Fulford and Marsden, 1998a,b; Weiss et al., 2004), although Weiss et al. (2004) do report that female isolates show greater conditioned-context fear behavior compared to group-reared rats. When isolation period, state of social deprivation, foot-shock and conditioning procedures, and strain are all taken into account, the only difference between Lukkes et al. (2009a) and the studies showing no effect of isolation-rearing on conditioned fear behavior for male rats is that the latter studies tested rats in a current state of social deprivation. Clearly, further work will be needed to clarify the relationship between isolationrearing and conditioned fear behavior.

\section{EFFECTS OF POST-WEANING SOCIAL ISOLATION ON HYPOTHALAMIC-PITUITARY-ADRENAL (HPA) AXIS FUNCTION}

Adverse early-life experiences in humans have lasting effects on the neuroendocrine stress axis, which are thought to increase the risk for the development of mood and anxiety disorders (Agid et al., 2000; Charney and Manji, 2004; Nemeroff, 2004). Chronic elevations in glucocorticoid release during early-life, resulting from stress-induced dysregulation of the hypothalamic-pituitary-adrenal (HPA) axis, may also have deleterious effects on neural physiology and behavior in adulthood (see Sapolsky et al., 2000). Interestingly, components of HPA axis and its neural regulators develop into the adult-like state from pre-weaning through adolescence (as recently reviewed by McCormick et al., 2009). Therefore, the study of HPA axis function during and following post-weaning social isolation may address whether post-weaning social isolation could be considered a stressor.

The effects of post-weaning social isolation on the HPA axis have produced mixed findings, with the majority of results suggesting little long-term effect of isolation-rearing (often combined with a state of social deprivation) on HPA axis functioning (as reviewed by Hall, 1998; Fone and Porkees, 2008). Specifically, Weiss et al. (2004) isolated Sprague-Dawley rats from PD21 and measured basal plasma adrenocorticotrophic hormone $(\mathrm{ACTH})$ and corticosterone levels in early adulthood (PD70) in a state of current social deprivation. Male isolates showed increased basal ACTH levels, while basal corticosterone levels for both male and female rats was unaffected by isolation/deprivation (Weiss et al.,
2004). A lack of effect of isolation-rearing on basal corticosterone levels in the presence of social deprivation was also observed by Schrijver et al. (2002) using an almost identical isolation protocol with Lister Hooded males. Additionally, Lukkes et al. (2009a) found no effect of isolation-rearing on basal corticosterone when male Sprague-Dawley rats were isolated from PD21 until PD42 and resocialized until testing in early adulthood (PD56). Thus, social isolation from pre-adolescence does not appear to have any effect on basal corticosterone levels regardless of rat strain or whether rats are sampled in current state of social deprivation. However, ACTH was not measured by Lukkes et al. (2009a), and it is possible that the heightened ACTH levels observed by Weiss et al. (2004) reflect increased HPA axis tone (Weiss et al., 2004). This has been supported indirectly by findings where male isolates show greater ACTH and corticosterone responses to acoustic startle stimuli (Weiss et al., 2004) or lower corticosterone levels $2 \mathrm{~h}$ after $10 \mathrm{~min}$ of restraint stress, indicative of greater negative feedback (Lukkes et al., 2009a). However, social isolation/deprivation did not alter adrenal weights or glucocorticoid or mineralocorticoid receptors in the hippocampus (Weiss et al., 2004), which is not consistent with the idea that social isolation is accompanied by greater HPA axis tone. Furthermore, in contrast to the effects of acoustic startle (Weiss et al., 2004), Schrijver et al. (2002) found that restraint stress did not reveal a difference in stress-induced ACTH or corticosterone between isolation-reared rats (PD21-PD84) tested in social deprivation vs. group-reared rats. This implies that the differential effects of stressors on HPA axis reactivity in isolates and group-reared rats may be stressor dependent. Overall, it is not clear whether isolation-rearing results in alterations to HPA axis activity and/or reactivity that could be indicative of chronic stress, and this area requires further experimentation. Furthermore, gender, isolation timing, state of social deprivation, plasma sampling times and stressor type should be considered as important variables.

\section{EFFECTS OF POST-WEANING SOCIAL ISOLATION ON MONOAMINERGIC SYSTEMS DEVELOPMENT OF MONOAMINERGIC SYSTEMS}

Significant remodeling of the human brain continues throughout childhood and adolescence, with cortical and subcortical structures showing peak increases in gray matter growth at approximately 8 11 years of age (Lenroot and Giedd, 2006) before declining to adult volumes. These changes in brain volume during childhood and adolescence are reflected in the increased production and progressive elimination of synapses and receptors (pruning), particularly in the monoaminergic pathways of the limbic system (Dinopoulos et al., 1997; Andersen, 2003) that influence emotional behavior. In rats, noticeable changes in the activity of DA and 5-HT systems are apparent from weaning to adolescence, with progressively increasing concentrations of 5-HT and its metabolite 5-hydroxyindoleacetic acid (5-HIAA) evident in the cortex, hippocampus, striatum and brainstem until mid-adolescence (PD45), from which they decline to pre-adolescent levels during adulthood (PD90; Chen et al., 1997). Similarly, striatal concentrations of DA and its metabolite 3,4-dihydroxyphenylacetic acid (DOPAC) increase until mid-adolescence (PD45; Chen et al., 1997), and DA release is also heightened in the basal ganglia during mid-adolescence relative to adulthood (Knoll et al., 2000). During these developmental 
periods, expression of DA receptors within specific terminal fields also changes markedly, with $D A D_{1}$ and $D_{2}$ receptors in the striatum and nucleus accumbens (NAc) progressively increasing in number up to early adolescence (PD28), prior to pruning to adult levels (Tarazi et al., 1998; but see Teicher et al., 1995). Similar patterns in increased production and subsequent decreased expression of these receptors in the medial prefrontal cortex (mPFC) have also been described, with peaks again seen in the pre- to mid-adolescent periods (Andersen et al., 2000; Brenhouse et al., 2008). Related developmental alterations in $\mathrm{mPFC} \mathrm{DA} \mathrm{D}_{2}$ autoreceptor function have also been demonstrated (Andersen et al., 1997), which, together with the increased numbers of DA $D_{1}$ receptors, may assist in maintaining an enhanced DA tone in this area as needed for effective acquisition of salience and appropriate modulation of goal-directed behaviors (Steketee, 2003; Grace et al., 2007; Brenhouse et al., 2008). Combined, these changes within monoaminergic systems from post-weaning onwards appear to help in preparing young animals for the expression of adolescent-typical behaviors (Spear, 2000), and as mentioned earlier, this developmental period is when play behavior emerges for rats (Panksepp, 1981). Furthermore, as suggested earlier, the pre- to mid-adolescent time period in which marked developmental alterations to monoamine systems occurs appears to be a critical period for the effects of post-weaning social isolation on male rat anxiety-related behavior.

\section{EFFECTS OF POST-WEANING SOCIAL ISOLATION ON LIMBIC SEROTONERGIC FUNCTION}

Serotonergic systems modulate anxiety-like behavior, and alterations to 5-HT pathways are thought to lead to the development of anxiety disorders (Lucki, 1998; Millan, 2003; Lowry et al., 2005). For instance, increased levels of 5-HT release and activity within the limbic system of rats are associated with heightened anxiety-like behavior in the EPM (Rex et al., 2004). Unlike the behavioral studies, there are few studies that either compare the effects of different post-weaning social isolation periods or compare the effects of social isolation with the effects of current state of social deprivation on the activity of monoamine systems. In fact, the majority of studies have assessed 5-HT function during chronic post-weaning social isolation (i.e. in current state of social deprivation). Thus, further studies are needed to ascertain whether isolation-rearing alone has long-term effects on 5-HT systems related to anxiety or fear behaviors.

For the most part, post-weaning social isolation affects 5-HT levels and activity in terminal regions of the rodent limbic system (Table 1). Rather than social isolation/deprivation producing global changes in limbic 5-HT levels or activity, region-specific effects can be observed. For example, although variance exists in the timing and duration of isolation, post-weaning social isolation generally appears to increase markers of serotonergic activity in the mPFC (Table 1). This includes increased 5- $\mathrm{HT}_{1 \mathrm{~A}}$ and 5- $\mathrm{HT}_{2 \mathrm{~A}}$ receptor binding (Gunther et al., 2008), enhanced 5-HT turnover (Brenes et al., 2008) and elevated tissue concentrations (Rilke et al., 1998a; Miura et al., 2002a,b). In contrast, 5-HT levels and release in the hippocampus appear to be reduced during post-weaning social isolation (with a presumptive compensatory increase in $5-\mathrm{HT}_{1 \mathrm{~A}}$ receptors), particularly when isolation was initiated in the pre-adolescent period (PD21-28; Table 1). Reduced serotonergic function in the hippocampus may relate to increased anxiety-like behavior observed during and following post-weaning social isolation (Lapiz et al., 2003). Studies of serotonergic activity in the rat amygdala are required following post-weaning social isolation, given that serotonergic activity in the central nucleus of the amygdala (CeA) may relate to heightened anxiety states by promoting behavioral, emotional and endocrine responses to stressors (see Mo et al., 2008). Post-weaning social isolation of other species, albeit in time periods outside of pre-adolescence (Table 1), increased serotonergic activity particularly in the CeA. Interestingly, administration of selective 5-HT reuptake inhibitors (SSRIs) during adulthood reverses many of the changes described in Table 1 (Rilke et al., 2001; Miura et al., 2005; Gunther et al., 2008; Brenes and Fornaguera, 2009), suggesting that SSRIs could be an effective pharmacotherapy for reversing anxiety-like behavioral deficits induced by isolation-rearing.

\section{EFFECTS OF POST-WEANING SOCIAL ISOLATION ON DOPAMINERGIC FUNCTION}

Alterations to DA activity during post-weaning social isolation are seen in many of the same anxiety-related limbic regions where 5-HT activity is also affected, as shown in Table 2. In the mPFC, DA innervation and turnover are generally decreased during postweaning social isolation, particularly when the isolation procedure was applied in pre-adolescence (PD21-28; Table 2). Also, dopaminergic activity or turnover appears to be generally increased in the NAc during post-weaning social isolation (Table 2). Interestingly, stress-evoked accumbal DA release is potentiated by decreased mPFC DA activity (Doherty and Gratton, 1996; Pascucci et al., 2007; Del Arco and Mora, 2008). Male rats reared in isolation from PD21 show greater foot-shock and conditioned stimulus-induced DA release in the NAc when tested in early adulthood (PD63, in a current state of deprivation; Fulford and Marsden, 1998b). Given the inverse relationship between $\mathrm{mPFC}$ and NAc DA activity (Doherty and Gratton, 1996; Pascucci et al., 2007; Del Arco and Mora, 2008), it is possible that reduced mPFC DA activity in isolated rats permits stronger stress-induced potentiation of accumbal DA release. Like the current state of the relationship between limbic 5-HT and isolation-rearing in rats, further work is required to determine the long-term consequences of isolation-rearing on DA systems by re-socializing rats prior to testing. Furthermore, critical windows of vulnerability need to be determined, and the precise relationship between isolation-induced DA alterations and behavior require clarification.

Deficits in adult behavioral states associated with post-weaning social isolation may emerge as a consequence of altered interactions between 5-HT and DA function within the limbic system. For example, approximately $20 \%$ of serotonergic terminals from the dorsal raphe nucleus (dRN; the source of serotonergic projections to the NAc) to NAc shell and core contact pre-synaptic DA terminals (Van Bockstaele et al., 1993; Broderick and Phelix, 1997), and 5-HT perfused into the NAc dose-dependently increases DA release via pre-synaptic mechanisms (Chen et al., 1991; Parsons and Justice, 1993). Post-weaning social isolation results in enhanced stress-induced or stress neuropeptide-induced 5-HT release in the NAc (Fulford and Marsden, 1998a; Lukkes et al., 2009b). Increased 
Table 1 | Effects of isolation rearing on serotonergic function within anxiety-related neural circuits.

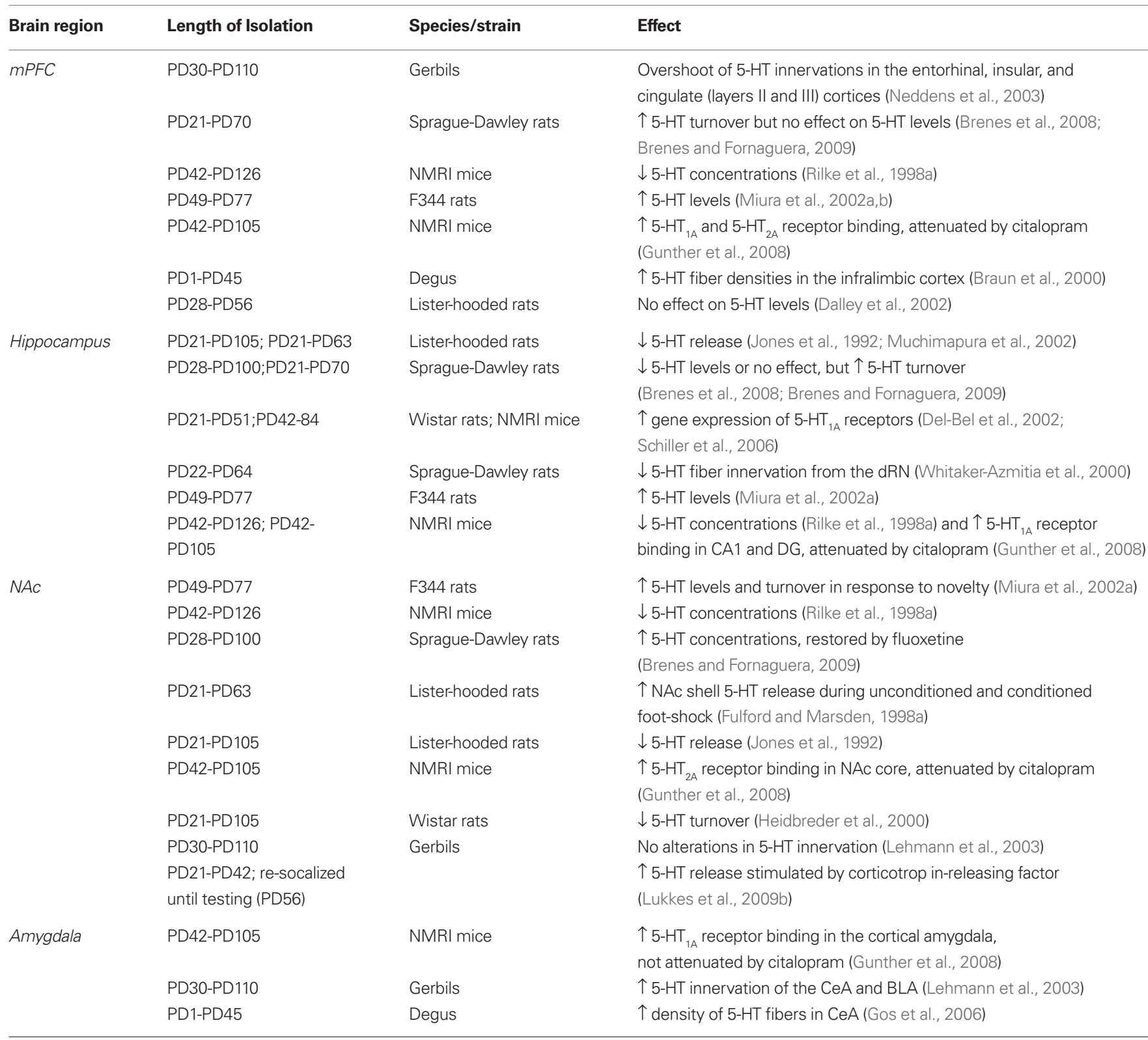

Animals were tested on the last day of isolation-rearing unless otherwise stated. Control groups comprised group-reared animals.

NAc 5-HT release may then facilitate NAc DA release in isolated rats, providing another mechanism by which stress-evoked DA release in the NAc is enhanced by post-weaning social isolation.

Further examples of relevant interactions between 5-HT and DA may be found within the mPFC. Pharmacological activation of $5-\mathrm{HT}_{1 \mathrm{~A}}$ receptors in the $\mathrm{mPFC}$ decreases $\mathrm{mPFC}$ DA release (DiazMataix et al., 2005). The increased 5- $\mathrm{HT}_{1 \mathrm{~A}}$ receptor binding and enhanced 5-HT turnover observed in the mPFC of isolation-reared rodents could inhibit DA release in the $\mathrm{mPFC}$, presumably due to direct inhibition of cortical pyramidal neurons that typically excite dopaminergic neurons of the ventral tegmental area, that in turn project to the mPFC (Diaz-Mataix et al., 2005). Interactions between 5-HT and DA also appear to be critical for the postnatal maturation of DA projection fields (Ferre et al., 1994; Moukhles et al., 1997; Mendlin et al., 1999). To illustrate, 5-HT has been shown to inhibit DA innervation of the mPFC during development (Neddens et al., 2003). Since 5-HT activity is generally increased in the mPFC during post-weaning social isolation (Table 1 ; albeit confounded with social deprivation), alterations to 5-HT activity in this region could account for the decreased DA innervation/activity observed in the $\mathrm{mPFC}$ of isolation-reared rodents (Table 2). Thus, the future challenges are to determine whether social isolation induces disruption of dopaminergic and serotonergic development within the extended limbic system, whether interactions between these systems are altered in the long-term by post-weaning social isolation, and which of these are related to subsequent changes to behavior. 
Table 2 | Effects of isolation rearing on dopaminergic function within anxiety-related neural circuits.

\begin{tabular}{|c|c|c|c|}
\hline Brain region & Length of Isolation & Species/strain & Effect \\
\hline \multirow[t]{6}{*}{ mPFC } & PD42-PD49 & NMRI mice & 个 DA metabolism (Rilke et al., 1998b) \\
\hline & PD1-PD45 & Degus & $\begin{array}{l}\downarrow \text { DA fibers in the precentral medial cortex, anterior cingulate cortex, } \\
\text { and prelimbic cortex (Braun et al., 2000) }\end{array}$ \\
\hline & PD49-PD77 & F344 rats & No effect on DA levels (Miura et al., 2002a,b) \\
\hline & PD28-PD56 & Lister-hooded rats & No effect on DA levels (Dalley et al., 2002) \\
\hline & PD21-PD111 & Nerr1-NULL mice & $\downarrow$ DA and DOPAC levels (Eells et al., 2006) \\
\hline & PD21-PD385 & Sprague-Dawley rats & No effect on DA release (Leng et al., 2004) \\
\hline Hippocampus & PD49-PD77 & F344 rats & No effect on DA levels (Miura et al., 2002a,b) \\
\hline \multirow{8}{*}{ NAc } & PD21-PD63 & Lister-hooded rats & $\begin{array}{l}\uparrow \text { NAc shell DA release during unconditioned and conditioned } \\
\text { foot-shock (Fulford and Marsden, 1998b) }\end{array}$ \\
\hline & PD21-PD105 & Lister-hooded rats & $\uparrow$ amphetamine-induced release of DA (Jones et al., 1992) \\
\hline & PD21-PD105 & Lister-hooded and Wistar rats & 个 DA turnover (Hall et al., 1998; Heidbreder et al., 2000) \\
\hline & PD21-PD105 & Lister-hooded rats & $\begin{array}{l}\downarrow \text { DOPAC, HVA, and DA turnover, but } \uparrow \text { DA levels (Weinstock et al., } \\
\text { 1978; Jones et al., 1992) }\end{array}$ \\
\hline & PD28-PD100 & Sprague-Dawley rats & No effect on DA levels (Brenes and Fornaguera, 2009) \\
\hline & PD21-PD105 & Lister-hooded rats & $\downarrow D_{2}$ DA receptors (Hall et al., 1998) \\
\hline & $\begin{array}{l}\text { PD21-PD105; } \\
\text { PD21-PD81 }\end{array}$ & $\begin{array}{l}\text { Lister-hooded, Sprague-Dawley, } \\
\text { and Fawn-Hooded rats }\end{array}$ & $\begin{array}{l}\text { No alterations in } D_{1} \text { or } D_{2} \text { DA receptors (Wilmot et al., 1986; Jones } \\
\text { et al., 1992; Del Arco et al., 2004; Djouma et al., 2006) }\end{array}$ \\
\hline & PD21-PD111 & Nerr1-NULL mice & $\downarrow D A$ levels and $\uparrow$ DA turnover (Eells et al., 2006) \\
\hline
\end{tabular}

Animals were tested on the last day of isolation-rearing.

Control groups comprised group-reared animals.

\section{LONG-LASTING EFFECTS OF SOCIAL ISOLATION ON CRF INTERACTIONS WITH 5-HT SYSTEMS CRF INTERACTIONS WITH 5-HT SYSTEMS AND EMOTIONAL BEHAVIOR}

Corticotropin-releasing factor is a neurotransmitter involved in integrating multiple components of the stress response (e.g. Dunn and Berridge, 1990a,b). Unlike the monoaminergic systems described above, the peak development of CRF systems appears to occur for the most part prior to weaning (Insel et al., 1988). For instance, CRF binding sites, CRF stimulation of adenylate cyclase activity, and CRF protein concentrations throughout the brain peak on PD8 and then decrease to adult levels by early adolescence (PD28) (Insel et al., 1988). Furthermore, CRF mRNA expression in the hypothalamic paraventricular nucleus reaches adult levels by PD8 and glucocorticoid negative feedback starts to affect CRF gene expression by PD8 as well (Korosi and Baram, 2008). In the hippocampus, CRF-immunoreactive neurons reach adult levels by PD18 (Chen et al., 2001). In the amygdala, specifically the CeA, CRF mRNA levels are detected as early as PD6 and continue to increase throughout development until adulthood (Vazquez et al., 2006). While occurring earlier than monoaminergic systems, these developmental trajectories do afford the opportunity for post-weaning social isolation to affect some aspects of CRF system development, particularly if initiated at earlier pre-adolescent time-points.

During exposure to stressors, CRF is released in the central nervous system (Merlo et al., 1995; Merali et al., 1998) and intracranial CRF administration induces the expression of behaviors resembling those caused by stress (Dunn and Berridge, 1990a,b). Previous studies have linked CRF with changes in 5-HT neuronal activity and 5-HT release (Price et al., 1998; Kirby et al., 2000; Price and Lucki, 2001; Forster et al., 2006, 2008; Lukkes et al., 2008). The $\mathrm{dRN}$ receives CRF projections from the CeA and bed nucleus of the stria terminalis (Gray, 1993), and CRF dose-dependently modulates $\mathrm{dRN}$ serotonergic activity via two receptor subtypes, $\mathrm{CRF}_{1}$ and $\mathrm{CRF}_{2}$ (Price et al., 1998; Kirby et al., 2000; Price and Lucki, 2001; Lukkes et al., 2008). It appears that CRF has opposing effects on 5-HT release (Kirby et al., 2000; Pernar et al., 2004; Lukkes et al., 2008) as mediated by the two CRF receptor subtypes. For instance, lower concentrations of CRF activate high-affinity $\mathrm{CRF}_{1}$ receptors in the dRN and result in decreased 5-HT release in the NAc (Lukkes et al., 2008). In contrast, higher concentrations of CRF infused into the dRN activate low-affinity $\mathrm{CRF}_{2}$ receptors to increase NAc 5-HT release (Lukkes et al., 2008). These receptors 
are located on both 5-HT and GABAergic neurons within the dRN (Day et al., 2004; Waselus et al., 2005), but the decrease in NAc 5-HT release may be through activation of $\mathrm{CRF}_{1}$ receptors located on 5-HT neurons within the dRN (Day et al., 2004), whereas activation of $\mathrm{CRF}_{2}$ receptors may inhibit local GABAergic interneurons, thereby disinhibiting 5-HT neurons within the dRN (Forster et al., 2008). Thus, disinhibition of 5-HT neurons could produce a CRF-mediated increase in NAc 5-HT release in response to the higher concentrations of CRF (Roche et al., 2003; Pernar et al., 2004; Forster et al., 2008). It is thought that CRF-mediation of 5-HT neurotransmission, in part, accounts for the anxiogenic and stress-related behavioral properties of CRF (Lowry et al., 2000, 2005; Price et al., 2002; Forster et al., 2006; Lowry and Moore, 2006; Mo et al., 2008).

While activation of central $\mathrm{CRF}_{1}$ receptors is associated with increased anxiety-like behavior in animal models (Heinrichs et al., 1997; Skutella et al., 1998; Timpl et al., 1998; Muller et al., 2003; Gehlert et al., 2005), the exact role of $\mathrm{CRF}_{2}$ receptors in mediating anxiety-related behaviors has not been clear (Takahashi, 2001). Studies of $\mathrm{CRF}_{2}$ receptor knockout mice suggest that $\mathrm{CRF}_{2}$ receptors may help reduce behavioral stress responses and anxiety-like behaviors (Bale et al., 2000; Bale, 2005). However, up-regulation of $\mathrm{CRF}_{2}$ receptors in the $\mathrm{dRN}$ is associated with an anxiogenic profile during amphetamine withdrawal in rats (Pringle et al., 2008). Furthermore, icv. administration of the $\mathrm{CRF}_{2}$ receptor agonist urocortin II increases anxiety-like behaviors in mice (Matsumoto et al., 2004). Moreover, icv. administration of antisauvagine-30, a $\mathrm{CRF}_{2}$ receptor-specific antagonist, decreases anxiety-like behavior in the EPM, conditioned freezing, and defensive-withdrawal paradigms (Takahashi et al., 2001). Antisauvagine-30 infused directly into the $\mathrm{dRN}$ prevents the behavioral effects of a learned helplessness paradigm when tested $24 \mathrm{~h}$ later (Hammack et al., 2003). Likewise, $\mathrm{CRF}_{2}$ receptor antagonism within the dRN also reduces the behavioral deficits associated with social defeat of adult hamsters (Cooper and Huhman, 2007). Overall, a role for $\mathrm{CRF}_{2}$ receptors in fear and anxiety-like behaviors may be region, stressor or even test specific, but the majority of studies suggest that activity of $\mathrm{CRF}_{2}$ receptors in the $\mathrm{dRN}$ is associated with increased fear or anxiety-like behaviors.

\section{EFFECTS OF POST-WEANING SOCIAL ISOLATION ON CRF-REGULATION OF MONOAMINERGIC SYSTEMS IN RELATION TO BEHAVIORAL DEFICITS}

Given the important role of CRF and 5-HT in modulating anxietylike behavior, we recently explored whether elevated social anxietylike behaviors observed in isolates could result from increased CRF receptor activation in the $\mathrm{dRN}$. Male rats exposed to 3 weeks of social isolation from weaning to mid-adolescence (PD21-42), followed by 2 weeks of re-socialization, show enhanced intra-dRN CRF-elicited NAc serotonergic responses as adults (Lukkes et al., 2009b). In addition, these rats showed increased $\mathrm{CRF}_{2}$ receptor levels in the lateral wings of the dRN (Lukkes et al., 2009b), which send projections to the NAc (Van Bockstaele et al., 1993). In contrast, no differences in $\mathrm{CRF}_{1}$ receptor levels were observed in either the lateral wings or medial portion of the dRN following isolation-rearing (Lukkes et al., 2009b). These findings support those suggesting a role for $\mathrm{CRF}_{2}$ receptors in the $\mathrm{dRN}$ in mediating heightened anxiety or fear states (e.g. Hammack et al., 2003; Pringle et al., 2008). Furthermore, the up-regulation of $\mathrm{CRF}_{2}$ receptors within the $\mathrm{dRN}$ of isolates is likely responsible for prolonged increases in NAc 5-HT release observed in isolates (Lukkes et al., 2009b). These findings also lead to the speculation that heightened CRF-mediation of 5-HT activity could be responsible for increased NAc 5-HT release in response to both foot-shock and conditioned cue presentation observed in isolated rats (PD21-PD63) when compared to group-reared controls (Fulford and Marsden, 1998a). Overall, these studies suggest that post-weaning isolation-rearing causes alterations in $\mathrm{CRF}_{2}$ receptor levels and sensitizes 5-HT release to both stressors and CRF, which could account for the increased fear and anxiety-like behavior exhibited by isolation-reared rats in adulthood. In line with this, recent data suggest that CRF receptor antagonism within the $\mathrm{dRN}$ reverses social anxiety-like behavior of male isolation-reared rats (PD21-42, re-socialized until testing at PD63), but does not affect the behavior of group-reared rats (Lukkes et al., 2009c). While the focus of recent studies has been CRF-mediation of 5-HT release in the NAc, the lateral wings of the $\mathrm{dRN}$ project to other anxiety-related circuits, such as the mPFC and CeA (Van Bockstaele et al., 1993). Therefore, increased $\mathrm{CRF}_{2}$ receptor levels in the lateral wings of the $\mathrm{dRN}$ found following post-weaning isolation-rearing (Lukkes et al., 2009b) are likely to have widespread consequences for stressor-induced 5-HT activity within the limbic system.

\section{SUMMARY AND FUTURE DIRECTIONS}

In summary, a comparison of social isolation onset and duration suggests that for male rats, social isolation that encompasses preadolescence is likely to result in increased anxiety-related behavior. However, a critical period of isolation for female rats is currently not apparent. The effects of social isolation on anxiety states do not appear to be masked by a current state of social deprivation at the time of testing, although social deprivation at the time of testing may affect conditioned fear responses (Lukkes et al., 2009a). Resocialization typically does not reverse the effects of pre-adolescent social isolation on anxiety behavior, suggesting the effects of this procedure on anxiety states are long-lasting. The proposed critical window for male social isolation (pre-adolescence) is a time of monoaminergic development and emergence of play behavior. Thus, it may be likely that disruption of the development and progression of these important factors by social isolation during pre-adolescence results in increased anxiety states, although this requires direct testing. Whether the long-term consequences of social isolation on anxiety states are related to isolation-induced alterations to HPA axis activity or reactivity has not been clearly determined. However, recent evidence suggests that post-weaning social isolation may increase behavioral and neurochemical sensitivity to stressors during adulthood by altering CRF-mediated serotonergic function in the limbic system. Overall, future research should consider narrowing post-weaning social isolation to a critical window of development, and should also consider whether the utilized procedures test the effects of post-weaning social isolation with or without the confound of a current state of social deprivation at the time of testing. Further research taking these considerations into account will likely elucidate some of the current discrepancies in outcomes from differences in post-weaning social isolation timing, particularly in relation to fear behaviors and neuroendocrine stress function. Nevertheless, the use of post-weaning social isolation of rats to produce behavioral outcomes similar to those 
of adverse early-life experiences in humans has proven fruitful, and has the potential to provide preclinical findings that may be translated into clinical research. Next, the differential effects of post-weaning social isolation on monoamine function as related to anxiety-related behavior between males and females requires clarification, given that females are more likely to suffer from affective disorders (Nestler et al., 2002; Becker et al., 2007).

The study of CRF-monoamine interactions following postweaning social isolation in rodents is a relatively new area that has promise in providing a mechanistic link between limbic monoamine function and anxiety-related behaviors following post-weaning social isolation. Future research specifically with the post-weaning social isolation model should elucidate the relationship between anxiety states and the expression and function of CRF receptor subtypes throughout the limbic system. At a more basic level, research is needed to fill the knowledge gap regarding the developmental

\section{REFERENCES}

Agid, O., Kohn, Y., and Lerer, B. (2000). Environmental stress and psychiatric illness. Biomed. Pharmacother. 54, 135-141.

Andersen, S. L. (2003). Trajectories of brain development: point of vulnerability or window of opportunity? Neurosci. Biobehav. Rev. 27, 3-18.

Andersen, S. L., Rutstein, M., Benzo, J. M., Hostetter, J. C., and Teicher, M. H. (1997). Sex differences in dopamine receptor overproduction and elimination. Neuroreport 8, 1495-1498.

Andersen, S. L., Thompson, A. T., Rutstein, M., Hostetter, J. C., and Teicher, M. H. (2000). Dopamine receptor pruning in prefrontal cortex during the periadolescent period in rats. Synapse 37, 167-169.

Arakawa, H. (2005). Interaction between isolation rearing and social development on exploratory behavior in male rats. Behav. Processes 70, 223-234.

Arakawa, H. (2007). Ontogenetic interaction between social relationships and defensive burying behavior in the rat. Physiol. Behav. 90, 751-759.

Bale, T. L. (2005). Sensitivity to stress: dysregulation of CRF pathways and disease development. Horm. Behav. 48, 1-10.

Bale, T. L., Contarino, A., Smith, G. W., Chan, R., Gold, L. H., Sawchenko, P. E., Koob, G. F., Vale, W. W., and Lee, K. F. (2000). Mice deficient for corticotropin-releasing hormone receptor-2 display anxiety-like behaviour and are hypersensitive to stress. Nat. Genet. 24, 410-414.

Becker, J. B., Monteggia, L. M., PerrotSinal, T. S., Romeo, R. D., Taylor, J. R., Yehuda, R., and Bale, T. L. (2007). Stress and disease: is being female a predisposing factor? J. Neurosci. 27, 11851-11855.
Braun, K., Lange, E., Metzger, M., and Poeggel, G. (2000). Maternal separation followed by early social deprivation affects the development of monoaminergic fiber systems in the medial prefrontal cortex of Octodon degus. Neuroscience 95, 309-318.

Brenes, J. C., and Fornaguera, J. (2009). The effect of chronic fluoxetine on social isolation-induced changes on sucrose consumption, immobility behavior, and on serotonin and dopamine function in hippocampus and ventral striatum. Behav. Brain Res. 198, 199-205.

Brenes, J.C., Padilla, M., and Fornaguera, J. (2009). A detailed analysis of openfield habituation and behavioral and neurochemical antidepressant-like effects in postweaning enriched rats. Behav. Brain Res. 197, 125-137.

Brenes, J. C., Rodriguez, O., and Fornaguera, J. (2008). Differential effect of environment enrichment and social isolation on depressivelike behavior, spontaneous activity and serotonin and norepinephrine concentration in prefrontal cortex and ventral striatum. Pharmacol. Biochem. Behav. 89, 85-93.

Brenhouse, H. C., Sonntag, K. C., and Andersen, S. L. (2008). Transient D1 dopamine receptor expression on prefrontal cortex projection neurons: relationship to enhanced motivational salience of drug cues in adolescence. J. Neurosci. 28, 2375-2382.

Broderick, P. A., and Phelix, C. F. (1997). I. Serotonin (5-HT) within dopamine reward circuits signals open-field behavior. II. Basis for 5-HT - DA interaction in cocaine dysfunctional behavior. Neurosci. Biobehav. Rev. 21, 227-260.

Charney, D. S., and Manji, H. K. (2004). Life stress, genes, and depression: multiple pathways lead to increased

programming of the different CRF receptors in anxiety-related neural circuits, and the mechanisms by which post-weaning social isolation results in increased $\mathrm{CRF}_{2}$ receptors in adulthood. Understanding the effects of post-weaning social isolation during critical developmental periods on CRF and related neuropeptides, and their modulation of monoaminergic activity in the limbic system, may direct novel therapeutic approaches to the treatment of anxiety disorders related to adverse early-life experiences.

\section{ACKNOWLEDGEMENTS}

This work was supported by NIH grants COBRE P20 RR015567, which is designated a Center for Biomedical Research Excellence, and R01 DA019921 (to GLF), but is solely the responsibility of the authors and does not necessarily represent the official views of NIH. CAL is supported by a 2007 NARSAD Young Investigator Award and an NSF CAREER award (NSF-IOS \#845550).

risk and new opportunities for intervention. Sci. STKE 2004, re5.

Chen, J. C., Turiak, G., Galler, J., and Volicer, L. (1997). Postnatal changes of brain monoamine levels in prenatally malnourished and control rats. Int. J. Dev. Neurosci. 15, 257-263.

Chen, J. P., van Praag, H. M., and Gardner, E. L. (1991). Activation of 5-HT3 receptor by 1-phenylbiguanide increases dopamine release in the rat nucleus accumbens. Brain Res. 543 354-357.

Chen, Y., Bender, R. A., Frotscher, M., and Baram, T. Z. (2001). Novel and transient populations of corticotropinreleasing hormone-expressing neurons in developing hippocampus suggest unique functional roles: a quantitative spatiotemporal analysis. J. Neurosci. 21, 7171-7181.

Cooper, M.A., and Huhman, K. L. (2007). Corticotropin-releasing factor receptors in the dorsal raphe nucleus modulate social behavior in Syrian hamsters. Psychopharmacology 194, 297-307.

Crespi, F., Wright, I. K., and Mobius, C. (1992). Isolation rearing of rats alters release of 5-hydroxytryptamine and dopamine in the frontal cortex: an in vivo electrochemical study. Exp. Brain Res. 88, 495-501.

Dalley, J.W., Theobald, D. E., Pereira, E. A., Li, P. M., and Robbins, T. W. (2002). Specific abnormalities in serotonin release in the prefrontal cortex of isolation-reared rats measured during behavioural performance of a task assessing visuospatial attention and impulsivity. Psychopharmacology 164, 329-340.

Day, H. E., Greenwood, B. N., Hammack, S. E., Watkins, L. R., Fleshner, M., Maier, S. F., and Campeau, S. (2004).Differential expression of 5HT-1A, alpha $1 \mathrm{~b}$ adrenergic, CRF-R1, and CRF-R2 receptor mRNA in serotonergic, gamma-aminobutyric acidergic, and catecholaminergic cells of the rat dorsal raphe nucleus.J. Comp. Neurol. 474, 364-378.

Del Arco, A., and Mora, F. (2008). Prefrontal cortex-nucleus accumbens interaction: in vivo modulation by dopamine and glutamate in the prefrontal cortex. Pharmacol. Biochem. Behav. 90, 226-235.

Del Arco, A., Zhu, S., Terasmaa, A. Mohammed, A. H., and Fuxe, K. (2004). Hyperactivity to novelty induced by social isolation is not correlated with changes in D2 receptor function and binding in striatum. Psychopharmacology 171, 148-155.

Del-Bel, E. A., Joca, S. R., Padovan, C. M. and Guimaraes, F. S. (2002). Effects of isolation-rearing on serotonin-1A and M1-muscarinic receptor messenger RNA expression in the hippocampal formation of rats. Neurosci. Lett. 332, 123-126.

Diaz-Mataix, L., Scorza, M. C. Bortolozzi, A., Toth, M., Celada, P., and Artigas, F. (2005). Involvement of 5-HT1A receptors in prefrontal cortex in the modulation of dopaminergic activity: role in atypical antipsychotic action. J. Neurosci. 25, 10831-10843.

Dinopoulos, A., Dori, I., and Parnavelas, J. G. (1997). The serotonin innervation of the basal forebrain shows a transient phase during development. Brain Res. 99, 38-52.

Djouma, E., Card, K., Lodge, D. J., and Lawrence, A. J. (2006). The CRF1 receptor antagonist, antalarmin, reverses isolation-induced upregulation of dopamine D2 receptors in the amygdala and nucleus accumbens of fawn-hooded rats. Eur. J. Neurosci. 23, 3319-3327.

Doherty, M. D., and Gratton, A. (1996). Medial prefrontal cortical D1 receptor 
modulation of the meso-accumbens dopamine response to stress: an electrochemical study in freely-behaving rats. Brain Res. 715, 86-97.

Dunn, A. J., and Berridge, C. W. (1990a). Is corticotropin-releasing factor a mediator of stress responses? Ann. N. Y. Acad. Sci. 579, 183-191.

Dunn, A. J., and Berridge, C. W. (1990b). Physiological and behavioral responses to corticotropin-releasing factor administration: is CRF a mediator of anxiety or stress responses? Brain Res. Brain Res. Rev. 15, 71-100.

Eells, J.B., Misler,J.A., and Nikodem, V. M. (2006). Early postnatal isolation reduces dopamine levels, elevates dopamine turnover and specifically disrupts prepulse inhibition in Nerrlnull heterozygous mice. Neuroscience 140, 1117-1126.

Einon, D. F., Humphreys, A. P., Chivers, S. M., Field, S., and Naylor, V. (1981). Isolation has permanent effects upon the behavior of the rat, but not the mouse, gerbil, or guinea pig. Dev. Psychobiol. 14, 343-355.

Einon, D. F., and Morgan, M. J. (1977). A critical period for social isolation in the rat. Dev. Psychobiol. 10, 123-132.

Einon, D. F., Morgan, M. J., and Kibbler, C. C. (1978). Brief periods of socialization and later behavior in the rat. Dev. Psychobiol. 11, 213-225.

Espejo,E.P.,Hammen,C.L.,Connolly, N. P., Brennan, P. A., Najman, J. M., and Bor, W. (2007). Stress sensitization and adolescent depressive severity as a function of childhood adversity: a link to anxiety disorders. J. Abnorm. Child Psychol. 35, 287-299.

Ferre, S., Cortes, R., and Artigas, F. (1994). Dopaminergic regulation of the serotonergic raphe-striatal pathway: microdialysis studies in freely moving rats. J. Neurosci. 14, 4839-4846.

Fone, K. C., and Porkees, M. V. (2008). Behavioural and neurochemical effects of post-weaning social isolation in rodents-relevance to developmental neuropsychiatric disorders. Biobehav. Rev. 32, 1087-1102.

Forster, G. L., Feng, N., Watt, M. J., Korzan, W. J., Mouw, N. J., Summers, C. H., and Renner, K. J. (2006). Corticotropin-releasing factor in the dorsal raphe elicits temporally distinct serotonergic responses in the limbic system in relation to fear behavior. Neuroscience 141, 1047-1055.

Forster, G. L., Pringle, R. B., Mouw, N. J., Vuong, S. M., Watt, M. J., Burke, A. R., Lowry, C. A., Summers, C. H., and Renner, K. J. (2008). Corticotropinreleasing factor in the dorsal raphe nucleus increases medial prefrontal cortical serotonin via type 2 receptors and median raphe nucleus activity. Eur. J. Neurosci. 28, 299-310.

Fulford, A. J., and Marsden, C. A. (1998a). Conditioned release of 5 -hydroxytryptamine in vivo in the nucleus accumbens following isolation-rearing in the rat. Neuroscience 83, 481-487.

Fulford, A. J., and Marsden, C. A. (1998b). Effect of isolation-rearing on conditioned dopamine release in vivo in the nucleus accumbens of the rat. J. Neurochem. 70, 384-390.

Gehlert, D. R., Shekhar, A., Morin, S. M., Hipskind, P. A., Zink, C., Gackenheimer, S. L., Shaw, J., Fitz, S. D., and Sajdyk, T. J. (2005). Stress and central Urocortin increase anxiety-like behavior in the social interaction test via the CRF1 receptor. Eur. J. Pharmacol. 509, 145-153.

Gos, T., Becker, K., Bock, J., Malecki, U., Bogerts, B., Poeggel, G., and Braun, K. (2006). Early neonatal and postweaning social emotional deprivation interferes with the maturation of serotonergic and tyrosine hydroxylaseimmunoreactive afferent fiber systems in the rodent nucleus accumbens, hippocampus and amygdala. Neuroscience 140, 811-821.

Grace, A. A., Floresco, S. B., Goto, Y., and Lodge, D. J. (2007). Regulation of firing of dopaminergic neurons and control of goal-directed behaviors. Trends Neurosci. 30, 220-227.

Gray, T.S. (1993). Amygdaloid CRF pathways. Role in autonomic, neuroendocrine, and behavioral responses to stress. Ann. N. Y. Acad. Sci. 697, 53-60.

Gunther, L., Liebscher, S., Jahkel, M., and Oehler, J. (2008). Effects of chronic citalopram treatment on 5-HT1A and 5-HT2A receptors in groupand isolation-housed mice. Eur. J. Pharmacol. 593, 49-61.

Gutman, D. A., and Nemeroff, C. B. (2003). Persistent central nervous system effects of an adverse early environment: clinical and preclinical studies. Physiol. Behav. 79, 471-478.

Hall, F. S. (1998). Social deprivation of neonatal, adolescent, and adult rats has distinct neurochemical and behavioral consequences. Crit. Rev. Neurobiol. 12, 129-162.

Hall, F. S., Huang, S., Fong, G. W., Sundstrom, J. M., and Pert, A. (2000). Differential basis of strain and rearing effects on open-field behavior in Fawn Hooded and Wistar rats. Physiol. Behav. 71, 525-532.

Hall, F. S., Wilkinson, L. S., Humby, T., Inglis, W., Kendall, D. A., Marsden, C. A., and Robbins, T. W. (1998). Isolation rearing in rats: preand postsynaptic changes in striatal dopaminergic systems. Pharmacol. Biochem. Behav. 59, 859-872.

Hammack, S. E., Schmid, M. J., LoPresti, M. L., Der-Avakian, A., Pellymounter, M. A., Foster, A. C., Watkins, L. R., and Maier, S. F. (2003). Corticotropin releasing hormone type 2 receptors in the dorsal raphe nucleus mediate the behavioral consequences of uncontrollable stress. J. Neurosci. 23, 1019-1025.

Heidbreder, C. A., Weiss, I. C., Domeney, A.M., Pryce, C., Homberg, J., Hedou, G., Feldon, J., Moran, M. C., and Nelson, P. (2000). Behavioral, neurochemical and endocrinological characterization of the early social isolation syndrome. Neuroscience 100, 749-768.

Heim, C., Newport, D. J., Mletzko, T., Miller, A. H., and Nemeroff, C. B. (2008). The link between childhood trauma and depression: insights from HPA axis studies in humans. Psychoneuroendocrinology 33 693-710.

Heinrichs, S. C., Lapsansky, J., Lovenberg, T. W., De Souza, E. B., and Chalmers, D. T. (1997). Corticotropinreleasing factor CRF1, but not CRF2, receptors mediate anxiogenic-like behavior. Regul. Pept. 71, 15-21.

Hellemans, K. G., Benge, L. C., and Olmstead, M. C. (2004). Adolescent enrichment partially reverses the social isolation syndrome. Brain Res. 150, 103-115.

Hoffmann, L. C., Schutte, S. R., Koch, M. and Schwabe, K. (2009). Effect of "enriched environment" during development on adult rat behavior and response to the dopamine receptor agonist apomorphine. Neuroscience 158, 1589-1598.

Insel, T. R., Battaglia, G., Fairbanks, D. W., and De Souza, E. B. (1988). The ontogeny of brain receptors for corticotropin-releasing factor and the development of their functional association with adenylate cyclase. J. Neurosci. 8, 4151-4158.

Jones, G. H., Hernandez, T. D. Kendall, D. A., Marsden, C. A., and Robbins, T. W. (1992). Dopaminergic and serotonergic function following isolation rearing in rats: study of behavioural responses and postmortem and in vivo neurochemistry. Pharmacol. Biochem. Behav. 43 17-35.

King, M. V., Seeman, P., Marsden, C. A. and Fone, K. C. (2009). Increased dopamine $\mathrm{D} 2 \mathrm{High}$ receptors in rats reared in social isolation. Synapse 63, 476-483.

Kirby, L. G., Rice, K. C., and Valentino, R. J. (2000). Effects of corticotropinreleasing factor on neuronal activ- ity in the serotonergic dorsal raphe nucleus. Neuropsychopharmacology 22, 148-162.

Knoll, J., Miklya, I., Knoll, B., and Dallo, J. (2000). Sexual hormones terminate in the rat: the significantly enhanced catecholaminergic/serotoninergic tone in the brain characteristic to the post-weaning period. Life Sci. 67, 765-773.

Korosi, A., and Baram, T. Z. (2008). The central corticotropin releasing factor system during development and adulthood. Eur. J. Pharmacol. 583, 204-214.

Lapiz, M.D., Fulford,A., Muchimapura, S., Mason, R., Parker, T., and Marsden, C. A. (2003). Influence of postweaning social isolation in the rat on brain development, conditioned behavior, and neurotransmission. Neurosci. Behav. Physiol. 33, 13-29.

Laviola, G., Macri, S., Morley-Fletcher, S., and Adriani, W. (2003). Risk-taking behavior in adolescent mice: psychobiological determinants and early epigenetic influence. Neurosci. Biobehav. Rev. 27, 19-31.

Lehmann, K., Lesting, J., Polascheck, D., and Teuchert-Noodt, G. (2003). Serotonin fibre densities in subcortical areas: differential effects of isolated rearing and methamphetamine. Brain Res. Dev. Brain Res. 147, 143-152.

Leng, A., Feldon, J., and Ferger, B. (2004). Long-term social isolation and medial prefrontal cortex: dopaminergic and cholinergic neurotransmission. Pharmacol. Biochem. Behav. 77, 371-379.

Lenroot, R. K., and Giedd, J. N. (2006). Brain development in children and adolescents: insights from anatomical magnetic resonance imaging. Neurosci. Biobehav. Rev. 30, 718-729.

Leussis, M. P., and Andersen, S. L. (2008). Is adolescence a sensitive period for depression? Behavioral and neuroanatomical findings from a social stress model. Synapse 62, 22-30.

Lowry, C. A., Johnson, P. L., HaySchmidt, A., Mikkelsen, J., and Shekhar, A. (2005). Modulation of anxiety circuits by serotonergic systems. Stress 8, 233-246.

Lowry, C. A., and Moore, F. L. (2006) Regulation of behavioral responses by corticotropin-releasing factor. Gen. Comp. Endocrinol. 146, 19-27.

Lowry, C. A., Rodda, J. E., Lightman, S. L., and Ingram, C. D. (2000). Corticotropin-releasing factor increases in vitro firing rates of serotonergic neurons in the rat dorsal raphe nucleus: evidence for activation of a topographically organized mesolimbocortical serotonergic system. J. Neurosci. 20, 7728-7736. 
Lucki, I. (1998). The spectrum of behaviors influenced by serotonin. Biol. Psychol. $44,151-162$.

Lukkes, J. L., Forster, G. L., Renner, K. J., and Summers, C. H. (2008). Corticotropin-releasing factor 1 and 2 receptors in the dorsal raphe differentially affect serotonin release in the nucleus accumbens. Eur. J. Pharmacol. 578, 185-193.

Lukkes, J. L., Mokin, M. V., Scholl, J. L., and Forster, G. L. (2009a). Adult rats exposed to early-life social isolation exhibit increased anxiety and conditioned fear behavior, and altered hormonal stress responses. Horm. Behav. $55,248-256$.

Lukkes, J. L., Summers, C. H., Scholl, J. L., Renner, K. J., and Forster, G. L. (2009b). Early-life social isolation alters corticotropin-releasing factor responses in adult rats. Neuroscience $158,845-855$.

Lukkes, J. L., Vuong, S. M., Scholl, J. L., Oliver, H., and Forster, G. L. (2009c). Corticotropin-releasing factor receptor antagonism within the dorsal raphe reduces social anxiety after early-life social isolation. J. Neurosci. 29, 9955-9960.

Matsumoto, Y., Abe, M., Watanabe, T., Adachi, Y., Yano, T., Takahashi, H., Sugo, T., Mori, M., Kitada, C., Kurokawa, T., and Fujino, M. (2004). Intracerebroventricular administration of urotensin II promotes anxiogenic-like behaviors in rodents. Neurosci. Lett. 358, 99-102.

McCormick, C. M., Mathews, I. Z., Thomas, C., and Waters, P. (2009). Investigations of HPA function and the enduring consequences of stressors in adolescence in animal models. Brain Cogn. (in press).

McFarlane, A., Clark, C. R., Bryant, R. A., Williams, L. M., Niaura, R., Paul, R. H., Hitsman, B. L., Stroud, L., Alexander, D. M., and Gordon, E. (2005). The impact of early-life stress on psychophysiological, personality and behavioral measures in 740 non-clinical subjects. J. Integr. Neurosci. 4, 27-40.

Mendlin, A., Martin, F. J., and Jacobs, B. L. (1999). Dopaminergic input is required for increases in serotonin output produced by behavioral activation: an in vivo microdialysis study in rat forebrain. Neuroscience 93 , 897-905.

Merali, Z., McIntosh, J., Kent, P., Michaud, D., and Anisman, H. (1998). Aversive and appetitive events evoke the release of corticotropin-releasing hormone and bombesin-like peptides at the central nucleus of the amygdala. J. Neurosci. 18, 4758-4766.

Merlo, P., Lorang, M., Yeganeh, M., Rodriguez, D., Raber, J., Koob, G., and Weiss, F. (1995). Increase of extracellular corticotropin-releasing factor-like immunoreactivity levels in the amygdala of awake rats during restraint stress and ethanol withdrawal as measured by microdialysis. J. Neurosci. 15, 5439-5447.

Millan, M. J. (2003). The neurobiology and control of anxious states. Prog. Neurobiol. 70, 83-244.

Miura, H., Qiao, H., Kitagami, T., Ohta, T., and Ozaki, N. (2005). Effects of fluvoxamine on levels of dopamine, serotonin, and their metabolites in the hippocampus elicited by isolation housing and novelty stress in adult rats. Int. J. Neurosci. 115, 367-378.

Miura, H., Qiao, H., and Ohta, T. (2002a). Attenuating effects of the isolated rearing condition on increased brain serotonin and dopamine turnover elicited by novelty stress. Brain Res. 926, 10-17.

Miura, H., Qiao, H., and Ohta, T. (2002b). Influence of aging and social isolation on changes in brain monoamine turnover and biosynthesis of rats elicited by novelty stress. Synapse 46, 116-124.

Mo, B., Feng, N., Renner, K., and Forster, G. (2008). Restraint stress increases serotonin release in the central nucleus of the amygdala via activation of corticotropin-releasing factor receptors. Brain Res. Bull. 76, 493-498.

Moukhles, H., Bosler, O., Bolam, J. P., Vallee, A., Umbriaco, D., Geffard, M., and Doucet, G. (1997). Quantitative and morphometric data indicate precise cellular interactions between serotonin terminals and postsynaptic targets in rat substantia nigra. Neuroscience 76, 1159-1171.

Muchimapura, S., Fulford,A. J., Mason, R., and Marsden, C. A. (2002). Isolation rearing in the rat disrupts the hippocampal response to stress. Neuroscience $112,697-705$.

Muller, M. B.,Zimmermann, S., Sillaber, I., Hagemeyer, T. P., Deussing, J. M., Timpl, P., Kormann, M.S., Droste, S. K., Kuhn, R., Reul, J. M., Holsboer, F., and Wurst,W.(2003).Limbic corticotropinreleasing hormone receptor 1 mediates anxiety-related behavior and hormonal adaptation to stress. Nat. Neurosci. 6, 1100-1107.

National Clearinghouse on Child Abuse and Neglect (2005). Longterm Consequences of Child Abuse and Neglect. Washington, DC, U.S. Department of Health and Human Services.

Neddens, J., Bagorda, F., Busche, A., Horstmann, S., Moll, G. H., Dawirs, R. R., and Teuchert-Noodt, G. (2003). Epigenetic factors differentially influence postnatal maturation of serotonin (5-HT) innervation in cerebral cortex of gerbils: interaction of rearing conditions and early methamphetamine challenge. Brain Res. 146, 119-130.

Neddens, J., Brandenburg, K., TeuchertNoodt, G., and Dawirs, R. R. (2001). Differential environment alters ontogeny of dopamine innervation of the orbital prefrontal cortex in gerbils. J. Neurosci. Res. 63, 209-213.

Nemeroff, C. B. (2004). Early-life adversity, CRF dysregulation, and vulnerability to mood and anxiety disorders. Psychopharmacol. Bull. 38(Suppl. 1), 14-20.

Nestler, E. J., Barrot, M., DiLeone, R. J., Eisch, A. J., Gold, S. J., and Monteggia, L. M.(2002).Neurobiology of depression. Neuron 34, 13-25.

Panksepp, J. (1981). The ontogeny of play in rats. Dev. Psychobiol. 14, 327-332.

Parker, V., and Morinan, A. (1986). The socially-isolated rat as a model for anxiety. Neuropharmacology 25, 663-664.

Parsons, L. H., and Justice, J. B., Jr. (1993). Perfusate serotonin increases extracellular dopamine in the nucleus accumbens as measured by in vivo microdialysis. Brain Res. 606, 195-199.

Pascucci, T., Ventura, R., Latagliata, E. C., Cabib, S., and Puglisi-Allegra, S. (2007). The medial prefrontal cortex determines the accumbens dopamine response to stress through the opposing influences of norepinephrine and dopamine. Cereb. Cortex 17, 2796-2804.

Pernar, L., Curtis, A. L., Vale, W. W., Rivier, J. E., and Valentino, R. J. (2004). Selective activation of corticotropin-releasing factor-2 receptors on neurochemically identified neurons in the rat dorsal raphe nucleus reveals dual actions. J. Neurosci. 24, 1305-1311.

Plotsky, P. M., Thrivikraman, K. V., Nemeroff, C. B., Caldji, C., Sharma, S., and Meaney, M. J. (2005). Long-term consequences of neonatal rearing on central corticotropin-releasing factor systems in adult male rat offspring. Neuropsychopharmacology 30 , 2192-2204.

Potegal, M., and Einon, D. (1989). Aggressive behaviors in adult rats deprived of playfighting experience as juveniles. Dev. Psychobiol. 22, 159-172.

Price, M. L., Curtis, A. L., Kirby, L. G., Valentino, R. J., and Lucki, I. (1998). Effects of corticotropin-releasing factor on brain serotonergic activity. Neuropsychopharmacology 18 , 492-502.

Price, M. L., Kirby, L. G., Valentino, R. J., and Lucki, I. (2002). Evidence for corticotropin-releasing factor regulation of serotonin in the lateral septum during acute swim stress: adaptation produced by repeated swimming. Psychopharmacology 162, 406-414.

Price, M. L., and Lucki, I. (2001). Regulation of serotonin release in the lateral septum and striatum by corticotropin-releasing factor. J. Neurosci. 21, 2833-2841.

Pringle, R. B., Mouw, N. J., Lukkes, J.L., and Forster, G. L. (2008). Amphetamine treatment increases corticotropinreleasing factor receptors in the dorsal raphe nucleus. Neurosci. Res. 62, 62-65.

Rex, A., Voigt, J. P., Gustedt, C., Beckett, S., and Fink, H. (2004). Anxiolytic-like profile in Wistar, but not SpragueDawley rats in the social interaction test. Psychopharmacology 177, 23-34.

Rilke, O., Freier, D., Jahkel, M., and Oehler, J. (1998a). Dynamic alterations of serotonergic metabolism and receptors during social isolation of low- and high-active mice. Pharmacol. Biochem. Behav. 59, 891-896.

Rilke, O., Jahkel, M., and Oehler, J. (1998b). Dopaminergic parameters during social isolation in low- and high-active mice. Pharmacol. Biochem. Behav. 60, 499-505.

Rilke, O., Will, K., Jahkel, M., and Oehler, J. (2001). Behavioral and neurochemical effects of anpirtoline and citalopram in isolated and group housed mice. Prog. Neuropsychopharmacol. Biol. Psychiatry 25, 1125-1144.

Roche, M., Commons, K. G., Peoples, A., and Valentino, R. J. (2003). Circuitry underlying regulation of the serotonergic system by swim stress.J. Neurosci. 23, 970-977.

Sapolsky, R. M., Romero, L. M., and Munck, A. U. (2000). How do glucocorticoids influence stress responses? Integrating permissive, suppressive, stimulatory, and preparative actions. Endocr. Rev. 21, 55-89.

Scheller-Gilkey, G., Woolwine, B. J., Cooper, I., Gay, O., Moynes, K. A., and Miller, A. H. (2003). Relationship of clinical symptoms and substance use in schizophrenia patients on conventional versus atypical antipsychotics. Am. J. Drug Alcohol Abuse 29, 553-566.

Schiller, L., Jahkel, M., and Oehler, J. (2006). The influence of sex and social isolation housing on pre- and postsynaptic 5-HT1A receptors. Brain Res. 1103, 76-87.

Schrijver, N.C., Bahr, N. I., Weiss, I.C., and Wurbel, H. (2002). Dissociable effects of isolation rearing and environmental enrichment on exploration, spatial 
learning and HPA activity in adult rats. Pharmacol. Biochem. Behav. 73, 209-224.

Skutella, T., Probst, J. C., Renner, U., Holsboer, F., and Behl, C. (1998). Corticotropin-releasing hormone receptor (type I) antisense targeting reduces anxiety. Neuroscience 85 , 795-805.

Spear, L. P. (2000). The adolescent brain and age-related behavioral manifestations. Neurosci. Biobehav. Rev. 24, 417-463.

Steketee, J. D. (2003). Neurotransmitter systems of the medial prefrontal cortex: potential role in sensitization to psychostimulants. Brain Res. Brain Res. Rev. 41, 203-228.

Takahashi, L. K. (2001). Role of CRF(1) and $\operatorname{CRF}(2)$ receptors in fear and anxiety. Neurosci. Biobehav. Rev. 25, 627-636.

Takahashi, L. K., Ho, S. P., Livanov, V., Graciani, N., and Arneric, S. P. (2001). Antagonism of CRF(2) receptors produces anxiolytic behavior in animal models of anxiety. Brain Res. 902, 135-142.

Tarazi, F. I., Campbell, A., and Baldessarini, R. J. (1998). Effects of hippocampal kainic acid lesions on striatolimbic dopamine D1-, D2-, and D4-like receptors. Neuroscience 87, 1-4.

Teicher, M. H., Andersen, S. L., and Hostetter, J. C., Jr. (1995). Evidence for dopamine receptor pruning between adolescence and adulthood in striatum but not nucleus accumbens. Brain Res. 89, 167-172.

Thorsell, A., Slawecki, C. J., El Khoury, A., Mathe, A. A., and Ehlers, C. L. (2006). The effects of social isolation on neuropeptide Y levels, exploratory and anxiety-related behaviors in rats. Pharmacol. Biochem. Behav. 83, 28-34.

Timpl, P., Spanagel, R., Sillaber, I., Kresse, A., Reul, J. M., Stalla, G. K., Blanquet, V., Steckler, T., Holsboer, F., and Wurst, W. (1998). Impaired stress response and reduced anxiety in mice lacking a functional corticotropinreleasing hormone receptor 1 . Nat. Genet. 19, 162-166.

Van Bockstaele, E. J., Biswas, A., and Pickel, V. M. (1993). Topography of serotonin neurons in the dorsal raphe nucleus that send axon collaterals to the rat prefrontal cortex and nucleus accumbens. Brain Res. 624, 188-198.

van den Berg, C. L., Hol, T., Van Ree, J. M., and Spruijt, B. M. (1999). Play is indispensable for an adequate development of coping with social challenges in the rat. Dev. Psychobiol. 34, 129-138.

Vazquez, D. M., Bailey, C., Dent, G. W., Okimoto, D. K., Steffek, A., Lopez, J. F., and Levine, S. (2006). Brain corticotrophin-releasing hormone $(\mathrm{CRH})$ circuits in the developing rat: effect of maternal deprivation. Brain Res. 1121, 83-94.

Waselus, M., Valentino, R. J., and Van Bockstaele, E. J. (2005).
Ultrastructural evidence for a role of gamma-aminobutyric acid in mediating the effects of corticotropin-releasing factor on the rat dorsal raphe serotonin system. J. Comp. Neurol. 482, 155-165.

Weinstock, M., Speiser, Z., and Ashkenazi, R. (1978). Changes in brain catecholamine turnover and receptor sensitivity induced by social deprivation in rats. Psychopharmacology 56, 205-209.

Weiss, I. C., Pryce, C. R., Jongen-Relo, A. L. Nanz-Bahr, N.I., and Feldon, J. (2004). Effect of social isolation on stressrelated behavioural and neuroendocrine state in the rat. Behav. Brain Res. 152, 279-295.

Whitaker-Azmitia, P., Zhou, F., Hobin J., and Borella, A. (2000). Isolationrearing of rats produces deficits as adults in the serotonergic innervation of hippocampus. Peptides 21, 1755-1759.

Wilmot, C. A., VanderWende, C., and Spoerlein, M. T. (1986). Behavioral and biochemical studies of dopamine receptor sensitivity in differentially housed mice. Psychopharmacology 89, 364-369.

Winterfeld, K. T., Teuchert-Noodt, G. and Dawirs, R. R. (1998). Social environment alters both ontogeny of dopamine innervation of the medial prefrontal cortex and maturation of working memory in gerbils (Meriones unguiculatus). J. Neurosci. Res. 52, 201-209.
Wright, I. K., Upton, N., and Marsden, C. A. (1991). Resocialisation of isolation-reared rats does not alter their anxiogenic profile on the elevated $\mathrm{X}$-maze model of anxiety. Physiol. Behav. 50, 1129-1132.

Conflict of Interest Statement: Dr. Gina Forster declares she was a recipient of a Lilly Educational Grant sponsoring the Sanford School of Medicine's Centennial Symposium held the summer of 2008. All other authors declare that the review was constructed in the absence of any commercial or financial relationships that could be construed as a potential conflict of interest. Furthermore, all authors have no financial gain related to the outcome of this review paper or the research described within.

Received: 02 May 2009; paperpending published: 26 May 2009; accepted: 05 August 2009; published online: 20 August 2009.

Citation: Lukkes JL, Watt MJ, Lowry CA and Forster GL (2009) Consequences of post-weaning social isolation on anxiety behavior and related neural circuits in rodents. Front. Behav. Neurosci. 3:18. doi: 10.3389/neuro.08.018.2009

Copyright (c) 2009 Lukkes, Watt, Lowry and Forster. This is an open-access article subject to an exclusive license agreement between the authors and the Frontiers Research Foundation, which permits unrestricted use, distribution, and reproduction in any medium, provided the original authors and source are credited. 